\title{
The Stroop effect and the myth of automaticity
}

\author{
DEREK BESNER, JENNIFER A. STOLZ, and CLAY BOUTILIER \\ University of Waterloo, Waterloo, Ontario, Canada
}

\begin{abstract}
A widespread view in cognition is that once acquired through extensive practice, mental skills such as reading are automatic. Lexical and semantic analyses of single words are said to be uncontrollable in the sense that they cannot be prevented. Over the past 60 years, apparently convincing support for this assumption has come from hundreds of experiments in which skilled readers have processed an irrelevant word in the Stroop task despite explicit instructions not to, even when so doing would hurt color identification performance. This basic effect was replicated in two experiments, which also showed that a considerable amount of semantic processing is locally controlled by elements of the task. For example, simply coloring a single letter instead of the whole word eliminated the Stroop effect. This outcome flies in the face of any automaticity account in which specified processes cannot be prevented from being set in motion, but it is consistent with the venerable idea that mental set is a powerful determinant of performance.
\end{abstract}

Many low-level human behaviors are automatic, in that a stimulus serves to elicit the behavior in the absence of conscious awareness or intention (e.g., an eye blink in response to a puff of air; the patellar reflex; the Babinski reflex). Learned behaviors such as reading are also widely argued to be automatic in a similar sense. For example, it is well established that identifying the color of an incongruent word (e.g., green letters spelling the word "red") is slower than identifying the color of a congruent word (e.g., green letters spelling the word "green"). This Stroop effect (Stroop, 1935) and its many variants have been explored empirically, theoretically, and computationally by cognitive and developmental psychologists, psycholinguists, neuropsychologists, and cognitive scientists in more than 500 papers over the past 60 years (see MacLeod's 1991 review). A core assumption of virtually all the theoretical accounts is that skilled readers process the irrelevant word without consciousness or intent. Reading the word is said to be automatic in the sense that readers cannot refrain from computing the meaning of the word despite explicit instructions not to do so: 1

Reading is such an automatic process that it is difficult to inhibit and it will interfere with processing other information about the word.

$$
\text { (Anderson, 1995, p. 100) }
$$

the automatization of word recognition allows much quicker reading... but also leaves us vulnerable to the

This work was supported by Grants A0998, OGP0183905, and EQP0187220 from the Natural Sciences and Engineering Research Council of Canada. Correspondence should be addressed to D. Besner, Department of Psychology, University of Waterloo, Waterloo, ON, Canada N2L 3G1 (e-mail: dbesner@watarts.uwaterloo.ca).
Stroop effect.... knowing about this effect is no protection-the processes are not open to control.

(Reisberg, 1997, p. 603)

A fail-safe demonstration of automaticity, in particular the automatic nature of accessing word meaning, involves the Stroop task.

(Ashcraft, 1994, p. 72)

the Stroop effect demonstrates that both the name and meaning of a word are processed by skilled readers even when they are trying hard not to process them.

(Rayner \& Pollatsek, 1989, p. 72)

The working assumption adopted here is that the received theoretical interpretation is unappealing because the conclusion that reading in this task is "automatic" is uncalled for. Many of the mental processes that humans engage in operate outside awareness, but that fact need not in itself make such processing inevitable. Our perspective is an old one: mental "set" determines the kind and extent of processing that is engaged. In particular, the notion that we favor here is that of mental set serving to bias processing at different levels in multilevel models (e.g., letter level, word level, semantic level):

Attention-like effects can be produced which greatly change the distribution of activation across the network, and in particular, the role of different levels of representation in the network, simply by biasing the gain between levels, without any structural reorganization.

(Henderson, 1987, p 190)

The experiments reported here are new; they provide a demonstration that a simple manipulation adapted from the study of putative automatic processes in the related domain of semantic priming during reading can serve to 
drastically reduce (Experiment 1 ) and even eliminate (Experiment 2) the Stroop effect in a variant of Stroop's (1935) original task.

\section{Semantic Priming Revisited}

Many of us regularly fail to note parallels between only slightly different domains of investigation. The relevant example here is that "automatic" semantic priming as it is seen in lexical decision when subjects simply read the prime (see Neely's 1991 review) can be drastically reduced, and even eliminated, if subjects are required to perform a letter search on the prime before responding to the target (see, e.g., Smith, Theodor, \& Franklin, 1983). The interpretation favored in the present paper is that the letter search prime task initiates a block between serially organized lexical and semantic levels of processing which acts to preserve activation in aid of explicit letter identification through feedback from the lexical level. The result is that lexical level processing (as indexed by repetition and morphemic priming) is preserved, but semantic priming is either drastically reduced in magnitude or eliminated (Friedrich, Henik, \& Tzelgov, 1991; Stolz \& Besner, 1996, in press).

This reduction/elimination of semantic priming has been reported repeatedly in the literature, beginning over a decade ago. Despite this, the implications for understanding whether semantic processing of the irrelevant word in the context of the Stroop task can be described as automatic (i.e., cannot be prevented) have gone virtually unnoticed. ${ }^{2}$ Indeed, MacLeod (1991) argued that the "real strength of automaticity theories lies in their ability to capture priming situations" and then noted that in Posner and Snyder's (1975) account, "priming occurs through the automatic spread of activation, essentially the same mechanism used to explain (Stroop) interference."

To reiterate, the published literature has not explicitly made the connection between the reduction/elimination of semantic priming in lexical decision following letter search on the prime and the potentially negative implications that this result has for the widespread view that computing the meaning of the irrelevant word in the context of the Stroop task is automatic. The present experiments address this issue directly.

\section{Predictions}

The predictions are straightforward. If the received view of automatic processing in Stroop-type experiments is correct, the irrelevant word will always be processed to the semantic level in skilled readers. Consequently, whether only a single letter or the entire word is colored should not affect the magnitude of the Stroop effect. In contrast, if the requirement to identify the color of a single letter is detrimental to processing the word to the semantic level, as suggested by the results of related experiments in the semantic priming paradigm discussed above, the magnitude of the Stroop effect in the letter condition should be smaller than in a condition in which all the letters are colored.
A pseudohomophone condition which consisted of letter strings like "bloo" was included to (1) assess the idea that the Stroop effect is normally larger for words than for the pseudohomophones (as would be expected if an orthographic code plays a role in word recognition). and (2) to determine whether the single-letter condition also served to impair semantic processing for pseudohomophones.

\section{EXPERIMENT 1}

\section{Method}

Subjects. Sixty-four undergraduates from the University of Waterloo were tested individually and paid $\$ 4.00$ each for their participation.

Stimuli. The stimuli consisted of the individual words red, blue, yellow, and green and their phonologically equivalent counterparts. wred, bloo, yeloe, and grene, displayed in lowercase on a color monitor. On half the trials, the stimuli were congruent (the color and the letter string referred to the same color), and on the remaining trials, they were incongruent. All congruent and incongruent color-letter-string pairings were utilized. The experiment was programmed in MEL (Schneider, 1988) on an IBM 486-66 computer with a color monitor. The four colors used (and their corresponding MEL codes) were red ( $R G B 42,0,0)$, blue (RGB $0,0,42$ ), green (RGB $0,42,0$ ), and yellow (RGB 63, 63, 21).

Procedure. On each trial, the subjects were presented with a single stimulus in the middle of the screen and were told to ignore the letter string and to identify which of the four colors it appeared in quickly and accurately. The subjects responded by pressing the appropriate color on the keyboard: the "z," " $x$," "> ," and "?" keys, which were covered, respectively, by red, blue, yellow, and green paper.

On half the trials, the entire letter string appeared in red, blue, green, or yellow. On the other half of the trials, only a single letter was red, blue, green, or yellow; the remaining letters appeared in gray ( $R G B 42,42,42$ ). The position of the single colored letter was chosen in order to ensure that different letter positions were sampled and balanced across congruent and incongruent pairings. Each subject saw a different random order of 288 test trials (36 trials in each of the 8 conditions), which were preceded by 72 practice trials whose composition mirrored the test trials.

\section{Results}

The correct reaction time (RT) data for each subject in each condition were trimmed to eliminate outliers with the use of the Van Selst and Jolicoeur (1994) procedure; $2.5 \%$ of the data were discarded as a result. The remaining RT data (expressed as means) and associated error rates can be seen in Table 1.

\section{Table 1}

Mean Reaction Times (Milliseconds) and Error Rates for Identifying Color, as a Function of Conditions in Experiment 1

\begin{tabular}{|c|c|c|c|c|}
\hline \multirow[b]{2}{*}{ Pairing } & \multicolumn{2}{|c|}{ All Letters Colored } & \multicolumn{2}{|c|}{ Single Letter Colored } \\
\hline & RT & $\% \mathrm{E}$ & RT & $\% \mathrm{E}$ \\
\hline \multicolumn{5}{|c|}{ Words } \\
\hline Incongruent & 789 & 4.4 & 793 & 4.8 \\
\hline Congruent & 686 & 2.3 & 721 & 3.3 \\
\hline Difference & 103 & 2.1 & 72 & 1.5 \\
\hline \multicolumn{5}{|c|}{ Pseudohomophones } \\
\hline Incongruent & 756 & 3.7 & 779 & 3.9 \\
\hline Congruent & 689 & 3.2 & 729 & 3.8 \\
\hline Difference & 67 & 0.5 & 50 & 0.1 \\
\hline
\end{tabular}


A 2 (congruent vs. incongruent) $\times 2$ (color level: all letters colored vs. single letter colored) $\times 2$ (string type: words vs. pseudohomophones) analysis of variance was carried out on these RT data. Congruent trials were faster than incongruent trials $\left[F(1,63)=142.0, M S_{\mathrm{e}}=4,693\right.$, $p<.001]$, and displays that were all colored were responded to faster overall than displays with only a single colored letter $\left[F(1,63)=26.1, M S_{\mathrm{e}}=3,183, p<.001\right]$. The main effect of string type was marginal $[F(1,63)=$ 3.6, $\left.M S_{\mathrm{e}}=2,935, p<.10\right]$, with words being slower overall than pseudohomophones. Two interactions were significant: There was a larger Stroop effect for words than for pseudohomophones [congruency $\times$ string type, $\left.F(1,63)=11.8, M S_{\mathrm{e}}=2,348, p<.001\right]$, and there was a larger Stroop effect when the entire stimulus display was colored than when only a single letter was colored [congruency $\times$ color level, $F(1,63)=4.6, M S_{\mathrm{e}}=4,340$, $p<.05]$. Neither the remaining two-way interaction nor the three-way interaction was significant $(F=1)$. Nothing in the pattern of the error data vitiated the pattern observed in the RT data.

\section{Discussion}

The results from Experiment 1 are quite clear. The single-coloredletter condition produced a significantly smaller Stroop effect than did the all-colored-word condition. If words are always read automatically in such a way that they activate the semantic level, the single-letter condition should have produced as much of a Stroop effect as did the whole-word condition. The fact that it produced a smaller Stroop effect suggests that the automatic reading hypothesis which has prevailed over the last six decades is too strong. ${ }^{3}$

The second finding is that the words yielded a larger Stroop effect than did the pseudohomophones, replicating previous work by Dennis and Newstead (1981). This result is consistent with the claim that phonological coding is not the only basis for computing semantics; orthography also plays a role. However, this experiment is not sufficiently analytic to determine whether orthography serves to activate semantics (independent of phonology), whether it plays a role after semantic activation, or whether it plays a role both before and after semantic activation.

\section{EXPERIMENT 2}

The results of Experiment 1 are satisfactory to the extent that they show a reduction in the magnitude of the Stroop effect when only a single letter is colored as compared with when the whole word is colored. This observation is sufficient to undermine the strong version of the automatic reading hypothesis that has dominated theoretical thinking. Still, these results are not entirely in line with the results from experiments in which subjects made a lexical decision to a target string following letter search on the prime, because in all of those experiments, the semantic priming effect was virtually eliminated. There are many possible accounts of this between-task difference, but here we will focus on the argument that the Stroop effect is quite sensitive to a constituent condition-namely, the presence of congruent trials (see, e.g., Lowe \& Mitterer, 1982; Tzelgov, Henik, Sneg, \& Baruch, 1996). The problem with including congruent trials is that they encourage subjects to read the irrelevant word (see
MacLeod \& McDonald [1995] for such evidence). Moreover, it is difficult to detect such behavior, because the subject does not make an overt error on congruent trials. Instead, the overt response is correct, even though the wrong dimension is controlling behavior. This reading strategy may be quite unconscious, but it permeates the entire experiment in that it also makes it harder to ignore the irrelevant word on incongruent trials as evidenced by the fact that the interference effect increases as the proportion of congruent trials increases (see, e.g., Tzelgov et al., 1996).

A better way to examine the automatic reading hypothesis in the context of the Stroop task is to use only conditions that give subjects no incentive to read the word. This is accomplished by discarding congruent trials and comparing the incongruent condition with a baseline condition. One difficulty here is that the issue of what constitutes an appropriate baseline has never been resolved (see, e.g., Neely, 1991). Indeed, some investigators even suggest doing without (Jonides \& Mack, 1984; Lindsay \& Jacoby, 1994). Given that the experimental design advocated here requires some form of baseline, we used nonwords. This baseline is more appropriate than the commonly used series of xxxs because it is more word-like. Still, we do not argue that it is the only baseline that should be used (another example would be a baseline consisting of words that are not color related).

The purpose of Experiment 2 was to demonstrate that when congruent trials are removed from the experiment and a neutral baseline is substituted, semantic processing as indexed by the Stroop effect is even more drastically curtailed by the single-letter manipulation than in Experiment 1.

\section{Method}

The stimuli consisted of the same words as in Experiment 1, the same colors, the same procedure, and the same equipment. The only difference was that all the pseudohomophones were discarded, as were all the congruent stimuli. Neutral stimuli consisting of the nonwords ret, yenile, grend, and blat replaced the congruent stimuli. These controls were chosen to match the incongruent stimuli on length and on the first two letters, given the repeated worry that a Stroop effect can result simply from the first two letters spelling a color word (see, e.g., Tzelgov et al., 1996).

The experiment now consisted of 144 randomly ordered trials (36 trials in each of the 4 conditions), which were preceded by 36 practice trials that mirrored the composition of the test trials. A new set of 64 subjects was recruited from the same population as in Experiment 1; they were tested individually, and each was paid $\$ 4.00$.

Table 2

Mean Reaction Times (Milliseconds) and Error

Rates to Identify Color as a Function of Conditions in Experiment 2

\begin{tabular}{lccccc} 
& \multicolumn{2}{c}{ All Letters Colored } & & \multicolumn{2}{c}{ Single Letter Colored } \\
\cline { 2 - 3 } \cline { 5 - 6 } \multicolumn{1}{c}{ Pairing } & $\mathrm{RT}$ & $\% \mathrm{E}$ & & $\mathrm{RT}$ & $\% \mathrm{E}$ \\
\hline Incongruent & 777 & 2.9 & & 783 & 2.9 \\
Neutral & 743 & 2.4 & & 784 & 3.0 \\
Difference & 34 & 0.5 & & -1 & -0.1 \\
\hline
\end{tabular}




\section{Results}

The same screening procedure for outliers as used in Experiment 1 led to $2.9 \%$ of the correct RTs being discarded. The remaining RT data (expressed as means) and associated error rates can be seen in Table 2 .

A 2 (incongruent vs. neutral) $\times 2$ (color level: single letter vs. all letters) analysis of variance was carried out on these RT data. This analysis yielded a main effect of incongruent versus neutral trials $\left[F(1,63)=6.3, M S_{\mathrm{e}}=\right.$ $2,791, p<.02]$ and a main effect of the single-lettercolored versus all-letters-colored contrast $[F(1,63)=13.8$, $\left.M S_{\mathrm{e}}=2,459, p<.001\right]$, as well as an interaction in which the Stroop effect was smaller in the single-letter condition than in the whole-word condition $[F(1,63)=$ $\left.6.7, M S_{\mathrm{e}}=3,019, p<.02\right]$. Nothing in the error data vitiated the pattern observed in the RT data.

\section{Discussion}

The results of Experiment 2 are clear. There was a 34-msec Stroop effect in the whole-word condition, and no Stroop effect $(-1 \mathrm{msec})$ in the single-letter condition. ${ }^{4}$ Eliminating the congruent trials and substituting neutral ones appears to make it possible for semantic level processing to be curtailed even more dramatically than in Experiment 1 .

The results of Experiment 2 are again inconsistent with the widespread view reiterated in over 500 journal articles, chapters, and textbooks that a Stroop effect occurs because unconscious/automatic processes cannot be prevented from computing the semantics of the irrelevant word. This result is also problematic for an implemented "connectionist" account of the Stroop effect (Cohen, Dunbar, \& McClelland, 1990; Cohen, Servan-Schreiber, \& McClelland, 1992) because the model does not appear to have a way to produce the present result. It is of course possible to modify the assumptions that were made and/or add new components to the architecture. We look forward to such modifications, because implementing even a few forms of mental set in a network model is likely to make an important contribution to our understanding of cognitive processes. Such modifications would be particularly useful if, at the same time, they also provided an account of both the reduction/elimination of semantic priming on the one hand, and the preservation of morphemic priming in lexical decision on the other, as discussed in the introduction.

Our account of the data from Experiments 1 and 2 is the same as the one we have offered for the related disappearance of semantic priming in lexical decision following letter search on the prime (Besner \& Stolz, 1995; Chiappe, Smith, \& Besner, 1996; Stolz \& Besner, 1996 in press). Explicit processing of a letter's form or color in the contex of a word is associated with letter and lexical level activation that is blocked from flowing strongly to the semantic level. Instead, lexical level activation feeds back to the letter level to enhance processing there. If this account is correct, it implies that activation in the word recognition system is limited; otherwise there would be no need to block it. We note that the idea of activation as a limited resource has also been promulgated elsewhere (e.g., Anderson, 1976).

\section{GENERAL DISCUSSION}

Whether the specific explanation advanced here and elsewhere for related phenomena is correct is less important than the general conclusion to be drawn from these two experiments. Contrary to the view expressed repeatedly over the past 60 years in the Stroop literature, at least some aspects of word recognition are not automatic. Specifically, the present results are consistent with the claim that it is possible to prevent the computation of semantics. The hundreds of previous demonstrations of a Stroop effect which involved semantic processing occurred because, on the view favored here, subjects fell back (albeit unconsciously) on the default mental set of processing the word to the semantic level despite instructions to the contrary. To put it another way, the literal context is more powerful than the instructions to ignore the word; the context reinstantiates reading in the sense of enabling a set of mental structures and the pathways that connect them. In the memory literature, this is referred to as "transfer appropriate processing" (e.g., Roediger, 1990). Nonetheless, as the present experiments show, at least some of these putatively automatic reading processes can be interfered with so that the Stroop effect is reduced (Experiment 1 ), and even eliminated (Experiment 2 ). The ability to produce this outcome would seem to fly in the face of any automaticity account in which specified processes cannot be prevented from being initiated.

More generally, the premature classification of some mental behaviors as automatic may discourage attempts to understand the underlying processes by providing a ready made explanation. At the same time, reinvoking the concept of "set" invites us to struggle with unresolved, but important and difficult, questions. How is set implemented and controlled in an unconscious, biological form of mind? And by what agent or committee?

\section{REFERENCES}

ANDERSON, J. (1976). Language, memory, and thought. Hillsdale, NJ: Erlbaum.

ANDERSON, J. (1995). Cognitive psychology and its implications. New York: W. H. Freeman.

AshCRAFT, M. H. (1994). Human memory and cognition. Harper Collins.

BESNeR, D., \& Stolz, J. A. (1995). The myth of automaticity. Paper presented to the 36th annual meeting of the Psychonomic Society, Los Angeles.

Cheesman, J., \& Merikle, P. M. (1985). Word recognition and consciousness. In D. Besner, T. G. Waller, \& E. McKinnon (Eds.), Reading research: Advances in theory and practice (pp. 311-352). Orlando, FL: Academic Press.

Chiappe, P. R., SMith, M. C., \& Besner, D. (1996). Semantic priming in visual word recognition: Activation blocking and domains of processing. Psychonomic Bulletin \& Review, 3. 249-253.

Cohen, J. D., Dunbar, K., \& McClelland, J. L. (1990). On the control of automatic processes: A parallel distributed processing account of the Stroop effect. Psychological Review, 97, 332-361.

Cohen, J. D., Servan-Schreiber, D., \& McClelland, J. L. (1992). A parallel distributed processing approach to automaticity. American Journal of Psychology, 105. 239-241.

DENNIS, I., \& NEWSTEAD, S. E. (1981). Is phonological recoding under strategic control? Memory \& Cognition, 9, 472-477.

Friedrich, F. J., HeNiK, A., \& Tzelgov, J. (1991). Automatic processes in lexical access and spreading activation. Journal of Experimental Psychology: Human Perception \& Performance, 17, 792 806.

Glaser, M. O., \& Glaser, W. R. (1982). Time course analysis of the Stroop phenomenon. Journal of Experimental Psychology: Human Perception \& Performance. 8, 875-894.

HENDERSON, L. (1987). Word recognition: A tutorial review. In M. Coltheart (Ed.), Attention and performance XII: The psychology of reading (pp. 171-200). Hillsdale, NJ: Erlbaum.

Henik, A., Friedrich, F. J., \& Kellogg, W. A. (1983). The dependence of semantic relatedness effects upon prime processing. Memory \& Cognition, 11, 366-373

JONIDES, J., \& MACK, R. (1984). On the costs and benefits of costs and benefits. Psychological Bulletin, 96, 29-44.

Kahneman, D., \& Henik. A. (1981). Perceptual organization and attention. In M. Kubovy \& J. R. Pomerantz (Eds.), Perceptual organization (pp. 181-211). Hillsdale, NJ: Erlbaum.

LINDSAY, D. S., \& JACOBY, L. L. (1994). Stroop process dissociations: The relationship between facilitation and interference. Journal of Experimental Psychologv: Human Perception \& Performance, 20, 219-234.

Logan, G. D., Zbrodoff, N. J., \& Williamson, J. (1984). Strategies in the color-word Stroop task. Bulletin of the Psychonomic Society. 22, 135-138. 
Lowe, D. G., \& Mitrerer, J. O. (1982). Selective and divided attention in a Stroop task. Canadian Journal of Psychology, 36, 684-700. MACLEOD, C. M. (1991). Half a century of research on the Stroop effect: An integrative review Psychological Bulletin, 109, 163-203.

MacLeod, C. M., \& MCDOnaLd, P. (1995). Facilitation in the Stroop task is artifactual. Paper presented at the 36 th annual meeting of the Psychonomic Society, Los Angeles.

MCCANn, R. S., Folk, C. L., \& Johnston, J. C. (1992), The role of spatial attention in visual word processing. Journal of Experimental Psychologv: Human Perception \& Performance, 18, 1015-1029.

NeELY, J. H. (1991). Semantic priming effects in visual word recognition: A selective review of current findings and theories. In D. Besner \& G. W. Humphreys (Eds.), Basic processes in reading: Visual word recognition (pp. 264-336). Hillsdale, NJ: Erlbaum.

PoSNER, M. I., \& SNyder, C. R. R. (1975). Attention and cognitive control. In R. L. Solso (Ed.), Information processing and cognition: The Lovola Symposium (pp. 55-85). Hillsdale, NJ: Erlbaum.

Rayner, K., \& Pollatsek, A. (1989). The psychology of reading. Englewood Cliffs, NJ: Prentice Hall.

REISBERG, D. (1997). Cognition: Exploring the science of the mind. New York: Norton.

ROEDIGER, H. L., III (1990). Implicit memory: Retention without remembering. American Psychologist, 45, $1043-1056$

SChNeIder, W. (1988). Micro Experimental Laboratory: An integrated system for IBM PC compatibles. Behavior Research Methods, Instruments, \& Computers, 20, 206-217.

Smith, M. C., Theodor, L., \& Franklin, P. E. (1983). On the relationship between contextual facilitation and depth of processing. Journal of Experimental Psychology: Learning, Memory, \& Cognition, 9, 697-712.

STolz, J. A., \& BESNER, D. (1996). The role of set in visual word recognition: Activation and activation blocking as nonautomatic processes. Journal of Experimental Psychology: Human Perception \& Performance, 22, $1166-1177$.

STOLz, J. A., \& BESNER, D. (in press). Levels of representation in visual word recognition: A dissociation between morphemic and semantic processing. Journal of Experimental Psychology: Human Perception \& Performance.

STroop, J. R. (1935). Studies of interference in serial verbal reactions. Journal of Experimental Psychologv, 18, 643-661.

Tzelgov, J., HeNik, A., SNEg, R., \& Baruch, O. (1996). Unintentional word reading via the phonological route: The Stroop effect with cross script homophones. Journal of Experimental Psychology: Learning, Memory, \& Cognition, 22, 336-349.

VAN SElst, M., \& Jolicoeur, P. (1994). A solution to the effect of sample size on outlier elimination. Quarterly Journal of Experimental Psychology, 47A, 631-650.

\section{NOTES}

1. The present paper addresses the issue of whether processing can be said to be automatic in the restricted sense that semantic activation cannot be prevented. We do not question the claim that (attentional) strategy effects can be overlaid on the standard Stroop effect (e.g., Cheesman \& Merikle, 1985; Logan, Zbrodoff, \& Williamson, 1984).

2. The closest is a report by Henik, Friedrich, and Kellogg (1983). In Experiments 3 and 4, they had subjects do a letter search through a prime display. A colored word appeared following an overt response to the prime display, and subjects had to identify the color of the word. There was little evidence that the semantic relation between the prime word and target word affected the time to identify the color of the word. Note, however, that the target words themselves were not color words.

3. Kahneman and Henik (1981) reported a finding very similar to the results of Experiment 1, and argued that it followed from the idea that attention is directed to objects. They concluded that coloring a single letter in comparison with a whole word serves to render the letter a perceptual object, thus reducing the size of the Stroop effect as compared with when the word is the perceptual object. There are, however, several difficulties with both their experiment and their theoretical argument.

The first difficulty is empirical. It is certainly true that Kahneman and Henik (1981) observed a reduction in the magnitude of the Stroop effect in their RT data for the single-letter condition as compared with the whole-word condition. Unfortunately, this reduction in the magnitude of the Stroop effect was accompanied by a doubling of the error rate. This apparent speed-error tradeoff makes such data difficult to interpret.

The second difficulty is theoretical. Given that the results of the experiments reported here conform to Kahneman and Henik's (1981) predictions, is their account sufficient? If the repetition, morphemic, and semantic priming literature discussed in the introduction is considered, we are inclined to the view that it is not. Friederich et al. (1991) reported that repetition priming is observed for words but not for nonwords following letter search on the prime (the same condition that eliminates semantic priming for words). The argument advanced by Friederich et al. is that the lexical level of representation is not impaired by letter search on the prime (hence priming for words but not for nonwords), but that semantic level processing is impaired (hence no semantic priming). It is not obvious how Kahneman and Henik's "perceptual object" account explains this. Relatedly, Stolz and Besner (in press) reported that morphemic priming was observed in lexical decision following letter search on the prime, but that semantic priming was not observed in the same experiment. Both the Friederich et al. and the Stolz and Besner findings seem better suited to an account in which "attention" (if an account which appeals to attention is needed) operates hierarchically in this context; lower levels (e.g., letter level, lexical level) need little or no attention as compared with higher levels (e.g., semantics).

Finally, this hierarchical notion is one way to integrate some of the data from the spatial cuing literature with the data from the letter search task, and the data reported here. That is, our hypothesis is that spatial attention, at least in the context of word recognition, plays a postlexical role in processing rather than the prelexical one envisioned by McCann, Folk, and Johnston (1992). Still, a more definitive answer to these questions awaits further investigation, because it is possible that the correct explanation for the data from the letter search prime paradigm does not apply to the present version of the Stroop paradigm, and one or the other of those paradigms might not index the same operations as the spatial cuing paradigm does.

4 . In both of these experiments, the single-letter condition was slower than the whole-word condition. Some might wonder whether the Stroop effect was reduced/eliminated because the conflicting semantic information was resolved during the extra time taken to deal with the single colored letter. Any account of this kind conflicts with the observation that displaying an incongruent color word prior to a target color patch still produces a Stroop effect (e.g., Cheesman \& Merikle, 1985; Glaser \& Glaser, 1982).

(Manuscript received November 22, 1996; revision accepted for publication January $31,1997$. 